\title{
The Roots of Technical Learning and Thinking: Situating TLT in Schools
}

\begin{abstract}
Ron Hansen
Technical thinking is defined as an aptitude, ingenuity, and affliction for solving practical problems through experience (Autio, Hansen, 2002). From the beginning of civilization such thinking has been a significant part of human existence (Burke \& Ornstein, 1995; White, 1962). Learning associated with it is a natural instinct for most people, young and old, who work in a technical field, pursue a practical hobby, or teach practical subjects. Historically the learning process, when formalized, involves apprenticing with a master who passes along the knowledge and competence by showing, doing, and discussing. Today such formal apprenticing is considered by many to be misplaced and inefficient. Why can't the knowledge and competencies associated with technical thinking be taught using computers and books?

A closer examination of the basic nature and form of technical thinking and the pedagogy that drives human thought about it helps address the question and underscores why the question, rather than apprenticeship or experiential learning itself, is misplaced. It is generally accepted in the education literature, classic and more recent, (Gamble, 2001; Lehmann, 2007; Willis 1974), that technical programs in schools are rooted in economic rather than social soil. Adolescents and young adults are "trained" with workplace skill, enculturation, and human capital in mind. Willis initially, and Lehmann more recently, refer to this pedagogy as "learning or choosing to labour."

The social soil is more difficult to understand. Cygnaeus, (cited in Kananoja, 1999) when he founded the Finnish school system in the $19^{\text {th }}$ century, was the earliest to articulate the social view. He pinpointed a human learning characteristic that he felt was central to the health and development of children and adults. Referring to the benefits of handwork for children Cygnaeus argued the pedagogical aim of technical learning was to develop the eye, the sense of
\end{abstract}

Ron Hansen (hansen@uwo.ca) is a Professor of Education at the University of Western Ontario, London, Ontario, Canada 
form, and general dexterity. Harre and Gillett (1994), one hundred years later, refer to this human tendency as having a "sense of physical location." They argue that perceptual and motor skill in the physical and material world give human beings a sense of self and intelligence.

Technology teachers in England, Germany, and Canada, a recent study (Hansen, 2002) concluded, were intimidated by the dominant academic milieu they found in schools. "Technology teachers, it was found, spend their careers unconsciously resisting a way of learning and behaving in their schools that, to them, is dysfunctional. As such their socialization into the profession is problematic." (p.10). The relative value of an experiential versus didactic pedagogy was a persistent issue. German technology teachers, by comparison, did not have to cope with status and stratification issues in their schools. There were none. Probing the roots of technical learning and thinking makes it possible to "reconsider" technical education in our schools.

\section{Research Method and Analysis}

In life-story research (Cole, 1991), the conversation between the investigator and the interviewee is usually dominated by the participant who is asked to freely recall and reflect on life experiences. The researcher, Cole asserted, maintains a passive role, merely probing these recollections and reflections. The purity of such accounts can range from strictly autobiographical to what Connelly and Clandinin (1990) call "collaborative stories." "And in our story telling, the stories of our participants merged with our own to create new stories, ones that we have labeled "collaborative stories"' (p. 12).

This research takes as its focus the process of autobiographical career reflection of one subject, "Sandy," for making sense of the shifts we all have to undertake in education. It makes use of the personal writing of one person who was selected because, although his career in many ways was atypical, he articulated some of the difficulties in adjustment which many technology teachers would not acknowledge because normally they don't question the school milieu into which they assimilate. He has documented a "critical incident" (Tripp, 1993) which influenced his career path and his disposition, both toward technology teaching and towards the nature of technical learning itself. The manuscript, using his critical reflection, sets the stage for other technology teachers to engage in similar reflection about their own development and enculturation.

A critical theorist perspective on schooling (Greenfield, 1993, McLaren, 1998) is used to provide context and understanding for this autobiographical research. The purpose of the research is to create insight and perspective for the reader, as well as to critically examine the assumptions upon which school curricula are based. What is the nature of technology and of teaching in schools? As nations and economies rush to claim a "knowledge-based" lifelong learning model, the need for technical education to have its true nature and form properly recognized and valued, in and out of formal learning institutions, is crucial. 


\section{Sanderson "Sandy" - Reconstructing Experiential Learning Tendencies}

Consensus on how people learn often eludes us as formally trained educators. We overlook or don't acknowledge what we know about how people learn from our own experiences. The following excerpt from Sandy's (a pseudonym) technological education journal conveys, with conviction, how learning occurs when it happens outside of the formal school environment. Readers will know of others from their own lives and experiences.

The most important insight which I learned about myself as a learner [in school] was that it did not matter to me what other people thought about my potential, I knew it was unlimited. Unfortunately I also came to oppose authority constantly. Many years passed before I began to respect people in authority. I was not aware of it at the time, but I demonstrated my true nature of learning, and emphasized in myself a return to the initial method of learning that all of us employ. I reconstructed my experiential learning tendencies. Unfortunately, the experience was not a good or constructive one and I became someone who would not trust or respect teachers until they could prove themselves to be a person who treated all others with respect and trust. Still to this day if anyone suggests that I am not capable of a task, I catch myself working hard to prove them wrong. In some ways this is good, but I have to pay close attention to my actions so as not to overreact.

From my perspective at the time (and I strongly believe this today) it became apparent to me that the most effective learning environment is one where the educator is able to set aside personal prejudice and focus on the needs of each individual. By doing so you can more effectively provide the area of individual attention that each student requires. This applies to all aspects of any work environment in which I have been employed. I certainly did not fully understand my learning tendencies then, but I am beginning to now. I am, by nature, a handson experiential learner and my schooling did not allow me to develop my learning style to any significant level from which my full potential could be realized. During my time in school my parents and teachers all emphasized how important it was to learn and do well in school. I did try to adapt my learning tendencies to suit their perceived views on how to study and learn, but I was only able to achieve limited success through these methods. This made school a difficult place for me to be because I did want to please my parents, but I was unable to explain or understand why I could not achieve the grade levels that we all knew I could. I was trying hard to adapt my learning style to what my parents and teachers thought it should be, and I did achieve limited success. 
What this journal vignette reveals is that the values and beliefs that differentiate academic studies from practical learning are discernible, but repressed. Sandy's reflections help the reader understand the dynamics of two distinct learning cultures, and their impact on situating technical learning in the school curriculum.

Sandy is particularly strong and articulate in expressing his less than stellar experience as a learner in schools. He had a number of demeaning experiences that, to this day, remain vivid in his memory. One could argue that he is ignoring the fact that many students experience problems or undergo some trauma in school life. In hindsight, many parents and students appreciate the discipline that school life imparts. On the other hand, some who think they are better off for schooling experiences may not have confronted their feelings fully or thought through what really happened. Sociologists are often quite blunt about the latent dysfunctions of the school. Bowles and Gintis (1976) argued, for example, that schools do not reduce or remove class inequities, they perpetuate them. At the individual student level, British sociologist Basil Bernstein (1970) argued that learning in schools serves middle class children (with strong linguistic orientations) well and deprives working class children (with strong non-discursive tendencies). "Thus the working class child may be placed at a considerable disadvantage in relation to the total culture of the school. It is not made for him [sic]: He [sic] may not answer to it." (p. 346). This point is further reinforced by the writings of Margaret Donaldson (1987): "The better you are at tackling problems without having to be sustained by human sense the more likely you are to succeed in our educational system, the more you will be approved of and loaded with prizes." (p. 78).

What this journal excerpt reveals, beyond personal growth, is that preparing to teach technology is complicated. What technology teachers are preparing for and practicing to do in their chosen profession is perplexing to them. They have, like many teachers, a set of baggage relating to their own schooling that may or may not be resolved in their own minds. What are my tendencies as a learner? What are my beliefs about learning, studying, and experiencing? These teachers experience a dissonance between value systems. Their success and self-esteem were measured, not by book studies and normative grading, but by experience and everyday technical, economic, political, and social reality. The view expressed by this technical teacher candidate eschews the way learning in schools is defined and perpetuated, and school life generally.

\section{Beyond Knowledge to Experience -}

\section{Examining the Assumptions Underlying Schooling}

The technology and general studies curriculum in secondary schools in the developed countries around the world is one that has evolved and is evolving in response to a range of pressures and perceived needs. The widespread belief is that industrial countries are in a significant economic transition and that formal education is the key to economic and social survival. "Skills for the New Economy" is the catch phrase across many fields/sectors (usually meant to be 
computer or information handling skills). Alternatives for organizing or improving the curriculum are discussed and debated but with little meaningful change to the general landscape. Some reviews of the classic curriculum literature (Bernstein, 1970; Donaldson, 1978; Eisner, 1998; Rogers, 1999; Sheridan, 2000) look at alternative ideas for organizing the curriculum in schools but those ideas never materialize. Why is this? Why are academic studies such a given in western societies? Why do subjects like technological education live in the shadow of academic studies? While the purpose here is not to answer these questions, Sandy's reflections give rise to them. The critical position taken by the author is that the knowledge transmission process in schools and the formal institutionalization of learning both displace rather than situate subjects like technology in the curriculum. A wholesale analysis of the heart and soul of the academic curriculum, and the educational sciences approach that created it, is overdue. Providing a critical examination of school knowledge, institutionalized learning, and the awkward position of technological education teachers like Sandy, are possible, but only when the assumptions upon which school curriculum is based open themselves to scrutiny.

Schooling assumes assimilation into society via academic achievement is an exclusive right and necessity for all citizens. This assumption is predicated on the notion that matters of the mind are superior to matters of the body and spirit. Evidence from recent research reports (Harre and Gillett, 1994, Kessels and Korthagen, 1996), however, suggests that the same "academic-diet-foreveryone" assumption is flawed. Assumptions like these lead to a devaluing of subjects like technology in the school, not to mention art, physical education, drama, and music. There are three assumptions that Sandy's testimony provokes us to consider in order to better understand the magnitude of the problem: a) book learning in schools is an irreproachable method by which to learn, b) an academic curriculum enhances human development and self-esteem, and c) a knowledge-based curriculum is superior to an experience-based one (Hansen, 1996, 2002). These will in elaborated in what follows.

Book learning in schools is an irreproachable method by which to learn.

Layton (1993) suggests technological education "challenges the historic role of schools as institutions which de-contextualize knowledge" (p. 15). Its [technological education] very essence is the antithesis of the general studies curriculum (including what is taught and how it is taught) in the comprehensive secondary school. More recent scholars (Noddings, 1995; Sheridan, 2000) suggested that new ways of thinking about learning, new ways of understanding the relation between learning and personal development, and new ways of structuring formal learning over the life-span, are worthy objectives. While these sentiments are welcomed, the evidence they marshal and the arguments they frame do not go far enough. When analyzed, their efforts confirm or reveal something that was identified by Borish (1991) in his study of schools in Denmark. That is, principles and practices that were originally conceived to be 
the founding philosophy of schools have been abandoned or eroded. Their [schools] purposes somehow became skewed and lost their realness. In his essay on how schooling contributes to a legitimacy of literacy at the expense of experience Sheridan exposes the problem:

For hundreds of years, knowledge and ways of knowing in most of settler culture (and longer, for some sectors of it) have included alphabetized, literate media. For thousands of years there has been an oral tradition in indigenous cultures. That is history. There is also the history of attitude here. Literacy and orality are valued and legitimized differently, and the difference in how we have valued those is part of our joint history. Schools teach literacy. There is no question that literacy is a good thing. The issue is the consequence of assuming that literate definition has priority (p. 23)

McLaren's (1998) argument that school systems in western society are not egalitarian, nor do they augment economic, cultural, and political structures is further evidence of the problem. A great opportunity to better understand what is missing in the life of school systems becomes possible when nothing is taken for granted and the needs of students and communities are put ahead of the needs of the government, industry, and school systems. One of the best historical examples of this phenomenon was documented in the Finnish school system.

Schooling, the Finnish scholar Lindfors (1999) concluded in her historical analysis of sloyd (learning of crafts), represents an artificial environment in which to achieve the grand goals that we all have for our youth, e.g., cognitive, emotional, and psychomotor growth. "When schools took over responsibility for teaching sloyd, the goals as well as the content became artificial. Sloyd was to offer material as well as formal education. Both the usefulness of learning sloyd skills (instrumental and economic aspects) and the fostering aspects were included in the educational goals of sloyd. In practice there was a contradiction between these two directions." (p. 14). Missing from our analysis of schooling, the author contended, is an honest assessment of the advantages and disadvantages that 12 years of institutional confinement and academic programming brings. Sociologists are one of the few groups who understand that schools perform positive and negative functions for society. The positive functions can be found in the school literature in the form of goals and purposes. The negative functions are not well understood or discussed widely. They include the "holding" function that schools perform on behalf of society, the conformity function, and the standardization function. The "Our schools/Ourselves" monograph series (1992) pointed out that schools construe learning in one way only. As graduates of our schools, most of us have come to accept that the way in which knowledge is packaged and dispensed in schools is a given. This "knowledge packaging and absorption process" may be problematic.

An academic curriculum enhances human development and self-esteem 
The assumption that book learning and an academic curriculum are essential to human development, fulfillment and self esteem is the most prominent and unchallenged assumption underlying schooling. The assumption implies that such learning enhances both personal and cognitive development. The universal belief is that there is a correlation between cognitive and personal development, and that academic endeavor is essential and exclusive to it.

Harre and Gillett (1994) have contributed significantly to the explanation of what enhances personal development in human beings. They refer to the importance of having a "sense of physical location." They conclude that having a sense of physical location is what leads to self-esteem, not academic accomplishment. Self-esteem is an essential ingredient that is often missing in young learners who find that life in school drains, rather than builds, their selfconfidence.

In technological education, learning involves utilizing a range of sensemaking capacities and assumes physical action, as well as knowledge acquisition, as essential components for understanding. Technology students have the chance to develop a practical wisdom much like that developed by technologists, engineers, and technicians in the workplace. Unfortunately their success in achieving this wisdom is tempered by the models of learning that are perpetuated in teacher education institutions and in general studies subject matter. The true pedagogy associated with practicing technology goes unheralded. This phenomenon is identified by Lindfors when she laments how the goals and content of sloyd became artificial when transferred to schools. The problem exists to this day in most western societies, not because of technology teachers who fail to recognize and do something about it, but because the curriculum framework and teaching methodology they are expected to adopt is philosophically too narrow to include their workplace and life experience preferences for learning. ${ }^{1}$

What Lindfors' work conveys is that existing conceptions of schooling/knowledge do not take into account other important variables that ultimately shape our development as human beings such as economic and workplace realities, cultural differences, and family diversities. In other words, schooling, by virtue of singling out specific aspects of knowledge for dissemination to our young is too narrow or oblique in its purpose to help children grow in the fullest sense. To be more complete, schools would have to cast human learning in a broader light to include, for example, learning about other ways of knowing.

Schools, Lindfors would say, cannot help but be artificial places because they are removed from everyday community reality and they do not attempt to

\footnotetext{
${ }^{1}$ This situation is especially acute in Canada, where technology teachers often are required to have work experience in their technical field before they can qualify for teaching. Their tendencies and preferences for learning are very much associated with the nature of problem solving in their respective workplace and technical field rather than with a school system prescribed formula for learning.
} 
relate school to life! School goals and content are constructed or manufactured. They are places where we simulate learning.

Knowledge-based curriculum is superior to an experience-based one.

Knowledge is the keystone or central element upon which institutionalized learning is based. This highly regarded commodity has been elevated to such a high degree over recent years that it is taken as a universal and exclusive standard for achievement and success. The irony is that most knowledge conveyed in formal education institutions is constructed knowledge. It is packaged, one might say, for delivery and consumption the same way a new product is for the retail market. It is referred to now as "school knowledge" (Eisner, 1992). There is a further problem. Its consumption does not lead to individual development, at least not for everyone. Knowledge in schools and in Western society is generally portrayed and legitimized at the expense of "experience" - life and work experience (Sheridan, 2000). Literature about the sociology of knowledge explains this irony quite effectively (McLaren, 1998). Conceptions of "experience," by comparison, do not exist and are not felt to be important. Experience is devalued compared to knowledge.

The assumption that knowledge-based learning leads to understanding is the single most prominent but unchallenged assumption we make as educators working in formal education institutions. This subtle but widespread hierarchy of growth, that information leads to knowledge and then to understanding, is flawed. The first part of the continuum is defensible. We do transfer much information to children in our school curriculum (especially so in this information society) and the sorting of that information does lead to a distillation, and to knowledge. The second part of the continuum is not defensible. It is impossible to achieve understanding from knowledge alone experience intervenes (Boud, 1989). Education philosophers like Dewey have documented the flaw in this assumption.

In the school context we exclude the world of experience as if it were somehow alien to students. Imagine a curriculum organized around problems as opposed to subjects, to human development rather than human differentiation. Experiential learning advocates (Kolb, 1984) have shown how human learning, when it is self-directed, is very much based in personal experience. But when it comes to youth, we put knowledge ahead of experience. The constructivist learning literature (Driver, 1989) suggests that young children do have an experience base onto which new learning can be attached. The irony is that our highly trained general studies teachers themselves have a narrow base of experience from which to draw. In Canada, this is very much the case. The teachers who enter the profession in our country are the high achievers from university systems. They are not required to have any work experience in their respective fields or disciplines. They have mastered a narrow conception of knowledge. Furthermore, their attraction and ultimate certification ensures that the system, as it is currently construed, perpetuates itself. 


\section{Discussion and Implications}

This analysis, rebellious as it is, sets the stage for a critical analysis of our reliance on knowledge versus experience in our policy and planning as educators; an honest and critical look at the premises we take for granted in the formal education system is possible. Sandy's journal entry implores us to rethink and clarify our assumptions about learning in schools generally, and the importance and place of technological education in that learning. Experience and knowledge need to be more transparent in our analysis of educational policy and planning. Experience needs to be considered as an "organizer" for curriculum in learning institutions and a more central and valued component in curriculum design. Challenging conventional thought about educational change is difficult. Technological education may be the one subject that challenges the academic tradition - a tradition that continues to de-contextualize knowledge as Layton stated. In short, technological education's most important role may be that of a barometer for reform in schools.

Experience and one's trust in it serves as a positive psychological factor or force in technical learning. The sense of self that Sandy exudes is central to meaningful learning and human growth. Remove it or diminish it, as we tend to do in schools for half the children, stifles both learning and human development rather than nurturing them. Educational psychologists believe knowledge can be acquired independent of practical action. Technology teachers, by comparison, know that such assertions need to be qualified. It might be safe to say that learning in controlled environments such as schools, (learning of a predominantly academic nature), can be separated from learning of a practical nature. That does not mean that such learning is suitable or best for students. Meaningful learning, when students are self-motivated or self-directed in their everyday lives, is extensively based in experience, as Boud attested. To further understand how technical learning has been displaced rather than situated in schools, critical analysis of formal institutionalized learning is necessary.

Reform of the knowledge-acquisition model of learning in schools may be more important that heretofore thought.

\section{References}

Autio, O. \& Hansen, R. (2002). Defining and measuring technical thinking: Students' technical abilities in Finnish comprehensive schools. Journal of Technology Education, 14(1), 5-20.

Bernstein, B. (1970). Education cannot compensate for society. New Society, 387, 344-347.

Borish, S. M. (1991). The land of the living: The Danish folk high schools and Denmark's non-violent path to modernization. Nevada City: Blue Dolphin Publishing, Inc.

Boud, D. (1989). Forward. In Susan Warner Weil and Ian McGill (Eds.). Making senseof experiential learning: Diversity in theory and practice. London: Open University Press. 
Bowles, S. and Gintis, H. (1976). Schooling in capitalist America. London: RKP

Burke, J., \& Ornstein, R. (1995). The axemaker's gift: A double edged history of human culture. New York: Putnam's.

Cole, A.L. (1991). Interviewing for life history: A process of on-going negotiation. In Ivor Goodson and Marshall Mangan (Eds.), Qualitative educational research studies: Methodologies in transition, Vol. I (pp. 185209). Research Unit on Classroom Learning and Computer Use in Schools, Occasional Papers, Faculty of Education, The University of Western Ontario, Canada.

Connelly, F.M. \& Clandinin, D.J. (1990). Stories of experience and narrative inquiry. Educational Researcher, 19(5), 2-14.

Donaldson, M. (1978). Children's minds. Glasgow: Fontana Press.

Driver, R. (1989). Students' conceptions and the learning of science. International Journal of Science Education, 11, 481-490.

Eisner, E. (1998). Forms of understanding and the future of educational research. In Ciaran Sugrue (Ed.), Teaching, curriculum, and educational research (pp. 161-169). Dublin: St. Patrick's College.

Gamble, J. (2001). Modelling the invisible: The pedagogy of craft apprenticeship. Studies in Continuing Education, 23(2), 185-200.

Greenfield, T.B. (1993). The man who comes back through the door in the wall: Discovering truth, discovering self, discovering organizations. In T. Greenfield \& P. Ribbing (Eds.), Greenfield on educational administration: Towards a humane science (pp. 92-119). London: Rutledge.

Hansen, R. (1996). The value of a utilitarian curriculum: The case of technological education. In Marc J. De Vries and Arley Tamir (Eds.). Shaping Concepts of Technology: From Philosophical Perspective to Mental Images (pp. 111-119). Dordrecht, Holland: Kluwer Academic Publishers.

Hansen, R. (2002). The socialization of technology teachers in England, Germany, and Canada: A comparative analysis. International Journal of Design and Technology Education 7(1), 10-18.

Hansen, R. (2002, May). Technological education policy and planning: Assumptions which need clarification. Proceedings of the international group of technological teacher educators. In E. Jarvinen, M. Lindh, E. Saaskilahti, \& J. Twyford (Eds.). Technology Education in Practice (pp. 3355). Seminar at the University of Oulu/Faculty of Education, University of Oulu, Oulu, Finland.

Harre, R. \& Gillett, G. (1994). The discursive mind. London: Sage Publications. Kessels, \& Korthagen, (1996). The relationship between theory and practice: Back to the classics. Educational Researcher, 25(3), 17-22.

Kananoja, T., (1999). Development of Finnish Technology Education. In T. Kananoja, J. Kantola, \& M. Issakainen (Eds.) Proceedings of the Development of Technology Education Conference, (pp. 17-32). Jyvaskyla, Finland: University Printing House of Jyvaskyla. 
Kolb, D. (1984). Experiential learning: Experience as the source of learning and development. Englewood Cliffs: Prentice-Hall.

Layton, D. (1993). Technology's challenge to science education. Buckingham: Open University Press.

Lehmann, W. (2007). Choosing to labour? School-work transitions and social class. Montreal \& Kingston: McGill-Queen's University Press.

Lindfors, L. (1999). Sloyd education in the cultural struggle. Part VIII. An outline of a sloyd educational theory. (Reports from the Faculty of Education, No. 4) Vasa: Abo Academic University, Department of Teacher Education.

Our Schools/Ourselves Educational Foundation, (1992). Monograph Series. Montreal: La maitresse d'ecole inc.

McLaren, P. (1998). Life in schools: An introduction to critical pedagogy in the foundations of education ( $3^{\text {rd }}$ ed.), (pp. 171-198). New York: Longmans.

Noddings. N. (1995). Teachers as models of educated persons. In S. Majhanovich (Ed.), Reforming teacher education: Problems and prospects, (pp. 33-45). London, Ontario: The Althouse Press.

Rogers, B. (1997). Informing the shape of the curriculum: New views of knowledge and its representation in schooling. Journal of Curriculum Studies, 29(6), 683-710.

Sanderson "Sandy" (2000). Practice teaching journal exercise (E 30/31). Faculty of Education, The University of Western Ontario. London, Canada.

Sheridan, J. (2000). The silence before drowning in alphabet soup. Canadian Journal of Native Studies. 18(1), 23-32.

Tripp, D. (1993). Critical incidents in teaching, London: Routledge.

White, L. (1962). Medieval technology and social change. Oxford: Clarendon Press.

Willis, P. (1974). Learning to labour: How working class kids get working class jobs. New York: Columbia University Press. 